\title{
A PEDOT-Coated Quantum Dot as Efficient Visible Light Harvester for Photocatalytic Hydrogen Production
}

\author{
Nagarajan Srinivasan $^{\mathrm{a}}$, Yuhiro Shiga ${ }^{\mathrm{a}}$, Daiki Atarashi ${ }^{\mathrm{a}}$, Etsuo Sakai ${ }^{\mathrm{a}}$ and Masahiro Miyauchi ${ }^{\mathrm{a}{ }^{\mathrm{b}} *}$ \\ a Department of Metallurgy and Ceramics Science, Graduate School of Science and Engineering, \\ Tokyo Institute of Technology, 2-12-1 Ookayama, Meguro-ku, Tokyo 152-8552, Japan \\ b Japan Science and Technology Agency (JST), PRESTO, 4-1-8 Honcho Kawaguchi, Saitama \\ 332-0012, Japan. \\ Corresponding author E-mail: mmiyauchi@ceram.titech.ac.jp
}

\begin{abstract}
The photocatalytic electrode device comprised of $\mathrm{Pt} / \mathrm{TiO}_{2} / \mathrm{CdS} / \mathrm{CdSe} / \mathrm{PEDOT}$ hybrid semiconductors exhibits stable and efficient hydrogen generation through photocatalytic watersplitting reactions. PEDOT polymer was electrochemically coated over a quantum dot-sensitized semiconductor and efficiently suppressed the back electron transfer from the semiconductor, thereby improving the photocurrent as compared to the uncoated control (13 vs $6 \mathrm{~mA} / \mathrm{cm}^{2}$, respectively). Impedance analysis revealed that the PEDOT-coated quantum dot electrode had reduced recombination resistance and increased electron lifetime values. Notably, the prepared electrode showed outstanding performance under visible-light irradiation in the absence of applied bias potential. Under this condition, the hybrid electrode structure generated hydrogen at a rate of $370 \mu \mathrm{mol} \mathrm{cm}{ }^{-2} \mathrm{hr}^{-1}$ with a sacrificial electrolyte. Furthermore, a quantum efficiency of 6.9\% and turnover number of 2210 were achieved by the PEDOT-coated electrode. The photostability test revealed that the PEDOT polymer coated electrode showed longer stability compared to the uncoated electrode. The findings presented in this report highlight the
\end{abstract}


advantages of designing and constructing the hybrid electrode structure and be applicable to other photocatalytic materials and photoelectrochemical reactions.

Keywords: quantum dots, polymer coating, photo-electrochemistry, solar energy conversion, hydrogen production

\section{Introduction}

Hydrogen is a promising energy source for clean and efficient energy applications. Photoelectrochemical hydrogen generation by semiconductors using solar energy has attracted considerable attention in various research fields. ${ }^{1-4}$ In particular, methods for the large-scale production of hydrogen from water without the concomitant emission of carbon dioxide are being actively developed. ${ }^{5}$ Novel photocatalyst architectures and efficiently designed electrodes that are capable of absorbing the wide range of solar energy spectrum are expected to facilitate photocatalytic water-splitting reactions for the effective hydrogen generation. The water-splitting activities have been investigated on wide-gap semiconductors such as $\mathrm{TiO}_{2}{ }^{6}$ and $\mathrm{SrTiO}_{3}{ }^{7}$ under UV light irradiation. Further, the development of visible-light-responsive photocatalysts capable of harvesting a wide range of the solar energy spectrum is highly desirable. The several visible light-responsive semiconductors, including $\mathrm{WO}_{3}{ }^{8}, \mathrm{Fe}_{2} \mathrm{O}_{3}{ }^{9}, \mathrm{BiVO}_{4}{ }^{10}, \mathrm{CaFe}_{2} \mathrm{O}_{4}{ }^{11}$, and $\mathrm{TaON}^{12}$, have been successfully constructed for water splitting applications.

Numerous reports during the past four decades have demonstrated the usefulness of metal chalcogenides quantum dots $\left(\mathrm{CdTe}^{13}, \mathrm{PbS}^{14}, \mathrm{CdS}^{15}\right.$, and $\left.\mathrm{CdSe}^{15}\right)$ for solar-driven water splitting owing to their narrow visible-light responsive band gap and high absorption coefficient ${ }^{16}$. These studies reported the efficient short circuit photocurrent ${ }^{17}$ and enhanced photo electrochemical 
reactions ${ }^{18}$. However, because of the inevitable photodegradation of quantum dots in aqueous medium, metal chalcogenide quantum dots are generally considered to be unsuitable for solardriven water-splitting applications. Although passivation layer coating has been reported to prevent the degradation of quantum dots ${ }^{15}$, such systems suffer from a lack of long-term stability, which is critical for the commercial viability as a photocatalytic semiconductor. In addition to the stability, electrode structure is very important for the development of quantum dots based solar water splitting. Recently the quasi artificial leaf electrode structure based on PbS quantum $\operatorname{dots}^{19}$ and dihydrolipolic acid as a capping agent to stabilize the light absorbing QDs (CdSe) for hydrogen evolution reaction were demonstrated ${ }^{20}$.These results indicate that quantum dot-based photoelectrode does not require layered p-n junction films like silicon solar cells, as photogenerated electrons and holes are efficiently separated at the interface between the quantum dots and mesoporous medium. The development of improved coating methods for quantum dots and more efficient electrode designs are necessary for highly photo stable systems that are suitable for practical application.

Herein, we establish a new design for efficient quantum dot based water-splitting systems with long-term stability. We have focused on the hole-conducting polymer poly (3,4ethylenedioxythiophene) (PEDOT), which has excellent electrocatalytic activity ${ }^{22,23}$ and electrochemical stability, ${ }^{22}$ as a material to inhibit the photo-degradation of CdS/CdSe quantum dots. The key feature of this approach is the use of PEDOT to synergistically prevent photodegradation of the CdS/CdSe (QDs) surface and to efficiently transport photogenerated holes to promote the desired hole-scavenging reactions. PEDOT allows the effective separation of photogenerated electrons and holes without any bias potential or solid state layered p-n junction like an expensive silicon solar cell. In the present report, we attempt to construct a robust 
electrode structure in aqueous solution and achieve efficient hydrogen generation under visiblelight irradiation with a sacrificial electrolyte.

\section{Experimental Section}

\subsection{Materials}

All of the reagent grade materials are procured from Kanto Chemicals \& Biological, Japan and were used for electrode preparation without further purification.

\subsection{Electrode preparation}

Mesoporous $\mathrm{TiO}_{2}$ film of $8 \mu \mathrm{m}$ thickness was prepared by screen-printing using commercial (P25) $\mathrm{TiO}_{2}$ nanoparticle paste onto the FTO glass substrates, followed by annealing at $500^{\circ} \mathrm{C}$ for $1 \mathrm{~h}$. Prior to $\mathrm{TiO}_{2}$ nanoparticle coating, the FTO substrates were coated by a compact thin layer of $\mathrm{TiO}_{2}(50 \mathrm{~nm})$ by spin coating method using titanium isopropoxide as a precursor material. The CdS and CdSe quantum dots sensitized onto a $\mathrm{TiO}_{2}$ electrodes by a successive ionic layer adsorption and reaction (SILAR) method. This SILAR method was similar to the procedure described in the previous papers ${ }^{1,2}$. $\mathrm{A} \mathrm{TiO}_{2}$ electrode was immersed into a $0.5 \mathrm{M}$ $\mathrm{Cd}\left(\mathrm{NO}_{3}\right)_{2}$ ethanol solution for $5 \mathrm{~min}$, washed with ethanol, and then immersed for another $5 \mathrm{~min}$ into a $0.5 \mathrm{M} \mathrm{Na}_{2} \mathrm{~S}$ methanol solution and washed with methanol. This two-step immersion procedure is termed as one SILAR cycle, and the crystallite growth of CdS were controlled by repeating the SILAR cycles. For CdSe quantum dots preparation, the sodium selenosulphate $\left(\mathrm{Na}_{2} \mathrm{SeSO}_{3}\right)$ is used as the Se source and preparation of $\mathrm{Na}_{2} \mathrm{SeSO}_{3}$ aqueous solution was followed by reported papers ${ }^{15,}{ }^{24}$. The CdSe quantum dots sensitization is resembled to that of CdS sensitization, except the immersion time $(1 \mathrm{hr})$ and constant temperature of $60^{\circ} \mathrm{C}$ should be 
maintain during electrode immersion in $\mathrm{Na}_{2} \mathrm{SeSO}_{3}$ solution and $\mathrm{Na}_{2} \mathrm{~S}$ solution. The SILAR cycles of CdS (5 cycles) and CdSe (3 cycles) quantum dots were optimized.

\subsection{Electropolymerisation of PEDOT polymer:}

The PEDOT polymer coated over $\mathrm{TiO}_{2} / \mathrm{QDs}$ electrodes were fabricated by an electropolymerization of EDOT (3,4-ethylenedioxythiophene) on $\mathrm{QDs} / \mathrm{TiO}_{2}$ electrode substrates using $\mathrm{LiClO}_{4}$ as supporting electrolytes, and acetonitrile as a solvent. The PEDOT concentration

was $1 \times 10^{-3} \mathrm{M}$, and the three-electrode cell was used for electropolymerization of PEDOT, where $\mathrm{TiO}_{2} / \mathrm{QDs}$ as working electrode, and saturated $\mathrm{Ag} / \mathrm{AgCl}$ and platinum foil were used as reference and counter electrodes, respectively. The electropolymerisation was carried out under room temperature in nitrogen atmosphere by purging the nitrogen gas which removes the dissolved oxygen from the electrolyte solution. The electropolymerisation was performed using pulse current method ${ }^{26}$, the anodic pulse current $(5 \mathrm{~mA}$ to $10 \mathrm{~mA})$ and cathodic pulse current (-3 $\mathrm{mA}$ to $-7 \mathrm{~mA}$ ) was adjusted and optimized with the electrode surface area. A second of anodic pulse, followed by another 1 second of cathodic pulse, and 5 seconds of zero current were applied (see our supplementary information, Figure S1). This above procedure is termed as one pulse cycle. To increase the PEDOT polymer coating thickness over $\mathrm{TiO}_{2} / \mathrm{QDs}$ electrode pulse cycles were repeated.

\subsection{Characterization and photoelectrochemical measurement:}

The morphology of the materials was observed using a transmission electron microscopy (TEM, JEM-2010F, JEOL Ltd. Japan.). EDX measurement was carried out by using Keyence VE 9800 SEM Microscope coupled with EDAX Genesis unit. The absorption spectra of the 
photoelectrode were measured on a UV Visible (UV-Vis) spectrophotometer (V -660, JASCO Ltd.) equipped with an integration sphere unit using diffuse reflection mode. The FTIR spectra were recorded by using Model IR-6100 apparatus (JASCO Ltd.).

The photoelectrochemical experiments were carried out using potentiostat/galvanostat (HZ-5000, Hokuto Denko Ltd.). The photocurrent density voltage (I-V) curve, electrochemical impedance spectroscopy and open circuit voltage decay measurements were carried out using three electrode systems, where the $\mathrm{TiO}_{2} / \mathrm{CdS} / \mathrm{CdSe} / \mathrm{PEDOT}$ working electrode, Pt plate as counter electrode and a saturated $\mathrm{Ag} / \mathrm{AgCl}$ was used as the reference electrode. The electrolyte solution containing $0.24 \mathrm{M} \mathrm{Na}_{2} \mathrm{~S}$ and $0.34 \mathrm{M} \mathrm{Na}_{2} \mathrm{SO}_{3}$ was used as sacrificial hole scavenger. A $150 \mathrm{~W}$ Xe lamp was used as the light source. The light was passed through a $430 \mathrm{~nm}$ optical UV cutoff filter, which pass out the wavelengths longer than $430 \mathrm{~nm}$ to illuminate the photoanode. The I-V curves were scanned for three times, and the average photocurrent densities for each scan were plotted. A frequency response analyzer (FRA) was used for EIS measurements using amplitude of $10 \mathrm{mV}$ over a frequency range from $40 \mathrm{kHz}$ to $1 \mathrm{mHz}$. The incident photon to current conversion efficiency (IPCE) measurement system was calibrated by silicon photodiode reference cell and the IPCE spectra were measured as function of wavelength from 400 to 800 $\mathrm{nm}$ at 0 bias voltages with a CEP-99W system (BUNKOH-KEIKI Co., Ltd. Japan). The IPCE of the samples was calculated from the equation 1 as follows, ${ }^{25}$

$$
\operatorname{IPCE}(\%)=\frac{1240 \times J\left[\mu \mathrm{A} / \mathrm{cm}^{2}\right]}{\lambda \times P\left[\mu \mathrm{W} / \mathrm{cm}^{2}\right]} \times 100
$$

where, $J$ is the photocurrent density generated by monochromatic light with wavelength $\lambda$ and intensity of Photon flux $(P)$. Photon flux was determined by using a standard silicon solar cell. 


\subsection{Photocatalytic hydrogen production}

In contrast to the photoelectrochemical measurement on a conventional two electrodes system, a novel $\mathrm{Pt} / \mathrm{TiO}_{2} / \mathrm{CdS} / \mathrm{CdSe} / \mathrm{PEDOT}$ wire free, efficient, single hybrid electrode system was designed and fabricated for photocatalytic hydrogen production. In this electrode design, Pt nanoparticles were firstly deposited over an FTO glass substrate by magnetron sputtering, followed by mesocopic $\mathrm{TiO}_{2}$, QDs and PEDOT polymer coating. The detailed experimental fabrication scheme of the hybrid electrode and the SEM cross section images of the fabricated electrode are shown in Figure $1 . \mathrm{H}_{2}$ evolution was measured by using closed gas-circulating system connected to a gas chromatogram. The FTO/Pt/TiO $/$ QQDS/PEDOT electrode area of 4 $\mathrm{cm}^{2}$ was placed in aqueous solution containing $0.24 \mathrm{M} \mathrm{Na}_{2} \mathrm{~S}$ and $0.34 \mathrm{M} \mathrm{Na}_{2} \mathrm{SO}_{3}$ acting as sacrificial electrolyte contained in a Pyrex glass beaker. The electrolyte solution and headspace were purged with argon gas and the cell was illuminated with a light source of $150 \mathrm{~W}$ Xe lamp with $430 \mathrm{~nm}$ cutoff filter. The evolved $\mathrm{H}_{2}$ gas was detected by on-line gas chromatography (Shimadzu Co., TCD, $5 \AA$ molecular sieves, Ar carrier gas). The amounts of generated $\mathrm{H}_{2}$ gas collected up to 6 hrs under light illumination were converted in to $\mu \mathrm{mol}$ for calculations.

\section{Result and Discussion}

TEM images of the $\mathrm{TiO}_{2} / \mathrm{QDs}$ and PEDOT polymer-coated $\mathrm{TiO}_{2} / \mathrm{QDs}$ are shown in Figure 2. The size of QDs particles were ranged from 5 to $10 \mathrm{~nm}$ in diameter (Figure 2 (a)). The TEM lattice fringe spacing proved that the CdS crystallite deposited on $\mathrm{TiO}_{2}$ and CdSe crystallite located at the surface of CdS (Figure 2(b)). From the Figure 2 (c) the PEDOT polymer coating layer was found to be approximately 2 to $5 \mathrm{~nm}$ in thickness and it uniformly covered the surface 
of the QDs and $\mathrm{TiO}_{2}$ semiconductor. The EDX elemental spot analysis were performed on with and without PEDOT polymer coated electrodes and the results are shown in Figure 3(a1) and 3(a2). The spot analysis results showed the elements like Cd, S, Se, Ti and O which confirms the presence of $\mathrm{CdS}$, CdSe and $\mathrm{TiO}_{2}$ semiconductor. In addition, the Figure 3(a2) showed the elemental peak of carbon (C) which corresponds to presence of PEDOT polymer coating over the semiconductor. The PEDOT coatings further probed by EDX mapping analysis are shown in Figure 3(b). The mapping results clearly revealed that the PEDOT polymer was uniformly coated over QDs/ $\mathrm{TiO}_{2}$ semiconductor surface.

In addition, PEDOT polymer coating over $\mathrm{TiO}_{2} / \mathrm{QDs}$ was confirmed by using FTIR analyses which are shown in Figure 4. The peaks at about 1525 and $1480 \mathrm{~cm}^{-1}$ are associated with $\mathrm{C}=\mathrm{C}$ asymmetric stretching vibration. The peak at $1360 \mathrm{~cm}^{-1}$ corresponds to $\mathrm{C}-\mathrm{C}$ and $\mathrm{C}=\mathrm{C}$ stretches of the thiophene ring. The peaks at about 1150 and $1105 \mathrm{~cm}^{-1}$ are assigned to the C-O$\mathrm{C}$ band stretching vibration. The peak at about $980 \mathrm{~cm}^{-1}$ can be assigned to the $\mathrm{C}-\mathrm{S}$ stretching vibration. All the peaks obtained can be attributed to the predominant role of PEDOT over the prepared electrode, indicating that PEDOT was successfully electrodeposited over $\mathrm{TiO}_{2 /} \mathrm{QDs}$ electrode. The FTIR spectrum of synthesized PEDOT electrode was roughly consistent with reported literatures ${ }^{27-29}$

Figure.5 shows photo-current density versus bias potential for the $\mathrm{TiO}_{2} / \mathrm{QDs}$ electrodes coated with different thicknesses of PEDOT. In this photo-electrochemical experiment, a Pt substrate was used as a counter electrode for hydrogen generation and $0.24 \mathrm{M} \mathrm{Na}_{2} \mathrm{~S}$ and $0.34 \mathrm{M}$ $\mathrm{Na}_{2} \mathrm{SO}_{3}$ (pH 12) acting as sacrificial electrolyte. The pure $\mathrm{TiO}_{2}$ and PEDOT electrodes did not generate photocurrent under visible light irradiation. We also performed I-V curve measurement under dark conditions (Supplementary Information S2), and all electrodes in the present study 
did not generate any current under dark condition. Under the light irradiation, it is noted that the PEDOT-coated $\mathrm{TiO}_{2} /$ QDs electrodes showed higher photocurrent density values as compared to uncoated $\mathrm{TiO}_{2} / \mathrm{QDs}$ electrodes like $\mathrm{TiO}_{2} / \mathrm{CdS}$, $\mathrm{TiO}_{2} / \mathrm{CdSe}$ and $\mathrm{TiO}_{2} / \mathrm{CdSe} / \mathrm{CdS}$. Although the UV-Vis spectra for $\mathrm{TiO}_{2} / \mathrm{QDs} / \mathrm{PEDOT}$ electrodes (Figure. 6) revealed that the PEDOT exhibited small inherent absorption from visible to infrared light, the action spectra of incident photon to current conversion efficiency (IPCE) exhibited the same spectra between the sample with PEDOT coating and that without PEDOT polymer (Figure 7). These results indicate that the inherent PEDOT absorption does not contribute the photocurrent generation. In the $\mathrm{TiO}_{2} / \mathrm{QDs} / \mathrm{PEDOT}$ system, the excited electrons are injected into the conduction band of $\mathrm{TiO}_{2}$ and subsequently migrate to the FTO layer, whereas the photogenerated holes react with the sacrificial agent through the PEDOT layer. The significant increase in current density exhibited by the PEDOT-coated electrodes can be ascribed to the effective charge separation between the QDs semiconductor and the electrolyte, a property that promoted efficient electron transfer to the counter electrode through the avoidance of recombination. However, further increases in the thickness of the PEDOT layer tended to reduce the current density due to impairment or insulation of the hole mobility. At the optimized thickness of the PEDOT (6 pulse times) coating, the $\mathrm{TiO}_{2} / \mathrm{QDs} / \mathrm{PEDOT}$ electrodes exhibited a current density value of $13 \mathrm{~mA} / \mathrm{cm}^{2}$ at $-0.2 \mathrm{~V}$ vs $\mathrm{Ag} / \mathrm{AgCl}$.

In addition to the effect of PEDOT coating, we observed the dependence of the coating order of QDs on the photocurrent properties. The photocurrent density of $\mathrm{TiO}_{2} / \mathrm{CdS} / \mathrm{CdSe}$ electrode was higher than that of $\mathrm{TiO}_{2} / \mathrm{CdSe} / \mathrm{CdS}$ electrode and these results indicated the stepwise band edge formation followed by the alignment of Fermi level at CdS/CdSe interface. ${ }^{15}$ Our IPCE measurement (Figure.7) also revealed that those of $\mathrm{TiO}_{2} / \mathrm{CdS}$ and $\mathrm{TiO}_{2} / \mathrm{CdSe}$ 
electrodes were $10 \%$ and $3 \%$. The higher IPCE $\%$ value for $\mathrm{TiO}_{2} / \mathrm{CdS}$ electrode indicated that the electron hole pair's separation and collection are efficiently taking place due to the interface between $\mathrm{CdS}$ and $\mathrm{TiO}_{2}$ has better junction and closer work function matching than that between CdSe and $\mathrm{TiO}_{2}$. The PEDOT polymer coated $\mathrm{TiO}_{2} / \mathrm{CdS} / \mathrm{CdSe}$ electrode showed efficient IPCE value (17.5\%) because its photoactive region extends up to $700 \mathrm{~nm}$ with efficient charge separation by the band alignment of semiconductors QDs and PEDOT polymer.

Further, the electron transport kinetics was investigated by an impedance spectroscopy (Figure 8). The EIS spectrums were analyzed and were fitted with appropriate equivalent circuit model. Figure 8(a) shows the Nyquist plot of the samples with and without PEDOT polymer coating. The presence of two semicircles in the uncoated sample can corresponds to the $\mathrm{Pt}$ counter electrode/ electrolyte and $\mathrm{TiO}_{2} / \mathrm{QDs} /$ electrolyte interface. However, in case of PEDOT coated electrode, the presence of a third additional semicircle can be attributed to the interaction between PEDOT polymer layer and ions present in the electrolyte solution. Figure 8(b1) shows the fitted equivalent circuit obtained for electrode without polymer coating as $R_{1}\left(R_{2} Q_{1}\right)\left(R_{3} Q_{2}\right)$ where, solution resistance $\left(\mathrm{R}_{1}\right)$, charge transfer resistance and double layer capacitance of $\mathrm{Pt}$ counter electrode $\left(\mathrm{R}_{2}, \mathrm{Q}_{1}\right)$ and $\mathrm{TiO}_{2} / \mathrm{QDs}\left(\mathrm{R}_{3}, \mathrm{Q}_{2}\right)$ form the major components of the circuit. While Figure 8(b2) represents the equivalent circuit as $R_{1}\left(R_{2} Q_{1}\right)\left(R_{3} Q_{2}\right)\left(R_{4} Q_{3}\right)$ for the PEDOT polymer coated $\mathrm{TiO}_{2} / \mathrm{QDs}$ electrode. In this case of $\mathrm{R}_{4}$ and $\mathrm{Q}_{3}$ represent the charge transfer resistance and double layer capacitance of the PEDOT polymer coated layer with electrolyte. The fitted equivalent circuits data for electrode without polymer coating showed higher charge transfer resistance values which indicate that the acceptability of electron recombination as the most difficult reaction taking place on the photoelectrode surface ${ }^{30}$. All three PEDOT polymer coated electrode show lower charge transfer resistance, which reveals that PEDOT polymer 
facilitate holes separation and effective blocking of the electron from the recombination process $^{31}$. Further, the EIS analysis data corroborate well with the I-V results.

In addition, the electron lifetime $(\tau n)$, as determined by the decay time with respect to the open circuit voltage (Voc) which are shown in Figure 8(c). The voltage-recombination lifetime was calculated from the equation 2 as follows, ${ }^{32,33}$

$$
\tau_{n}=-\frac{k_{B} T}{e}\left(\frac{d V_{O C}}{d t}\right)^{-1}
$$

where $k_{B}$ is Boltzmann's constant, $T$ is the temperature, $V_{o c}$ is the open circuit voltage, and $e$ is the elementary charge. The Figure 8(c) revealed that the $V_{\text {oc }}$ decay rate for the $\mathrm{TiO}_{2} / \mathrm{QDs}$ electrode decreased rapidly as compared to that of the PEDOT-coated electrode. The calculated electron lifetime of the PEDOT-coated $\mathrm{TiO}_{2} / \mathrm{QDs}$ electrode was markedly higher than that of the $\mathrm{TiO}_{2} / \mathrm{QDs}$ electrode, indicating that the PEDOT polymer coating efficiently enhances charge transport and reduces recombination of electron-hole pairs.

The stability of the PEDOT-coated $\mathrm{TiO}_{2} / \mathrm{QDs}$ electrode photocurrent over time in the presence of a sulfur sacrificial agent, under illumination with $>420 \mathrm{~nm}$ light is shown Figure 9. The initial photocurrent density of $\mathrm{TiO}_{2} / \mathrm{QDs}$ was slightly lower than that of $\mathrm{TiO}_{2} / \mathrm{QDs} / \mathrm{PEDOT}$ because of charge carrier recombination of QDs without PEDOT coating. ${ }^{34}$ After $9 \mathrm{~h}$ of continuous illumination, the photocurrent density of $\mathrm{TiO}_{2} / \mathrm{QDs}$ electrodes had markedly deteriorated. However, in the case of the PEDOT-coated $\mathrm{TiO}_{2} / \mathrm{QDs}$ electrode, the initial photocurrent was one-fold higher compared to the uncoated electrode and the current density was highly stable for $9 \mathrm{~h}$. The photostability of PEDOT-coated $\mathrm{TiO}_{2} / \mathrm{QDs}$ electrode was highest among the reported QD semiconductors electrode for photo-electrochemical water splitting ${ }^{18,35-}$ 
37. The PEDOT coating increased the stability of the photocurrent by accepting photogenerated holes from QDs, thereby effectively inhibiting the oxidative degradation of QDs. PEDOT is an effective organic hole conductor in light-emitting diodes and organic solar cells, ${ }^{38}$ and is extremely stable in the presence of water or oxygen molecules as compared to uncoated QDs. The present results indicate that PEDOT-coated $\mathrm{TiO}_{2} / \mathrm{QDs}$ electrodes retain their stability during water-splitting reactions.

For photocatalytic hydrogen evolution reaction, the modification of a semiconductor with co-catalyst such as platinum (Pt) nanoparticles is generally required for the multi-electron reduction to generate hydrogen molecules $\left(\mathrm{H}_{2}\right)$. In addition, previous studies have reported utilizing wire contacts between separated photoanodes and Pt electrodes to generate $\mathrm{H}_{2} \cdot{ }^{39}$ To overcome these problems of complicated electrode structures with additional exoergic bias application, we developed a novel wire-free electrode for efficient $\mathrm{H}_{2}$ generation without any bias potential (see our detailed preparation scheme and SEM cross-sectional images shown in Figure 1). On the basis of our spectroscopic and photo-electrochemical results mentioned above, the expected electric structure and charge transfer reactions of the $\mathrm{TiO}_{2} / \mathrm{QDs} / \mathrm{PEDOT}$ electrode for hydrogen generation are shown in Figure 10. The prepared wire free electrode was immersed in sacrificial sulfur electrolyte and exposed to visible-light illumination. Under these conditions, photogenerated electrons would be rapidly transferred from QDs to $\mathrm{TiO}_{2}$ and would also be injected into Pt active centers, resulting in $\mathrm{H}_{2}$ generation. The porous nature of the electrode is critical for $\mathrm{H}_{2}$ production activity, as protons in aqueous solution efficiently diffuse from the surface to the underlying Pt layer. Simultaneously, the photogenerated holes extracted from the PEDOT polymer traverse through the electrolyte for oxidation reactions. 
The hydrogen generation properties of PEDOT-coated and uncoated electrodes were shown in Figure 11(a). The obtained results confirmed that the PEDOT-coated electrode exhibited a higher generation rate than the latter. These trends were similar to the photocurrent results. It is noteworthy that the hydrogen generation rate of the uncoated $\mathrm{TiO}_{2} / \mathrm{QDs}$ electrode decreased as a result of photodegradation. In contrast, the hydrogen generation rate of the PEDOT-coated $\mathrm{TiO}_{2} / \mathrm{QDs}$ electrode was relatively constant for the first $3 \mathrm{~h}$, but then gradually deceased at a similar rate to the uncoated electrode, as shown in Figure 11(a). This behavior can be ascribed to the consumption of the sacrificial sulfur electrolyte through hole scavenging reactions. Finally, the calculated hydrogen evolution rate from the PEDOT polymer-coated electrode under visible-light irradiation reached $1.1 \mathrm{mmol} / \mathrm{cm}^{2}$ (6 h). The hydrogen generation rates of these electrodes were measured when we evacuated gas phase reactor and added the sacrificial agent in the electrolyte (Figure 11(b)). These results further demonstrate the stability and reproducibility of the PEDOT-coated $\mathrm{TiO}_{2} /$ QDs electrode for water splitting.

On the basis of our hydrogen generation value for the PEDOT-coated $\mathrm{TiO}_{2} / \mathrm{QDs}$ electrode $\left(1.1 \mathrm{mmol} / \mathrm{cm}^{2}\right.$ over $\left.6 \mathrm{~h}\right)$, the quantum efficiency and turnover numbers were calculated using the following equations 3 and 4, 3, 40-42

$$
\begin{gathered}
\text { Internal Quantum Efficiency }(\varphi)=\frac{\text { Number of reacted electrons }}{\int_{300}^{800} \text { Number of absorbed photons. } \mathrm{d} \lambda} \mathrm{X} 100 \\
=\frac{\text { Number of evolved } \mathrm{H} 2 \text { molecules } \mathrm{x} 2}{\int_{300}^{800} \text { Number of absorbed photons. } \mathrm{d} \lambda} \mathrm{X} 100 \quad \ldots \ldots . . . \text { (3) }
\end{gathered}
$$


Here, the number of evolved $\mathrm{H}_{2}$ molecules (moles $/ \mathrm{cm}^{2} / \mathrm{sec}$ ) was quantified and we considered the two electron transfer mechanism for the generation of one molecule of $\mathrm{H}_{2}$. It was assumed that all incident photons were absorbed by the reaction system. The corresponding absorption values measured form UU-Vis reflectance of QDs and the light spectrum of Xe lamp from $300 \mathrm{~nm}$ to $800 \mathrm{~nm}$ was recorded by radiometer, we estimated the number of absorbed photon numbers.

Turn Over Number $($ TON $)=\frac{\text { Number of reacted Photoelectrons }}{\text { Amount of Photocatalyst }}$

$=\frac{\text { Molar quantity of evolved hydrogen molecules x } 2}{\text { Molar quantity of Photocatalyst }}$

The turnover number is defined as the number of a product divided by the number of active sites on catalyst surface. Generally active sites in heterogeneous photocatalyst (our electrode system CdS/CdSe quantum dots) are difficult to quantify. Here, we considered that the total molar quantity of the catalyst as the number of active sites ${ }^{3}$. So carefully measuring the weight of the electrodes before and after CdS, CdSe coating, the loaded CdS and CdSe quantum dots final weights were evaluated. From the calculated weights, amount of QDs are estimated at $2.07 \times 10^{-6} \mathrm{M}(\mathrm{CdS})$ and $2.09 \times 10^{-6} \mathrm{M}(\mathrm{CdSe})$, respectively.

The calculated quantum efficiency of the reaction was $6.9 \%$ and the turn over number (TON) was greater than 2200. To our knowledge, these values are the highest reported to date among QD semiconductors electrode for photo-electrochemical water splitting under visiblelight illumination ${ }^{43}$. Further, the TON was calculated with respect to the hydrogen evolution 
interval time and the results are given in Table (Supplementary Information T1). The PEDOTcoated $\mathrm{TiO}_{2} / \mathrm{QDs}$ electrode showed higher TON as compared to that of $\mathrm{TiO}_{2} / \mathrm{QDs}$ electrode without PEDOT. Currently, we are working for more effective materials and electrode structures, such as the Z-scheme, for complete water splitting based on the promising system comprised of QD and PEDOT described here.

\section{Conclusion}

The PEDOT polymer-coated $\mathrm{TiO}_{2} / \mathrm{QDs}$ electrodes showed enhanced photo-stability and increased photocurrent due to reduced photo-degradation and efficient charge transfer. Based on the $\mathrm{Pt} / \mathrm{TiO}_{2} / \mathrm{QDs} / \mathrm{PEDOT}$ hetero-structure, we designed a unique electrode structure that displayed the highest hydrogen generation rate among QD semiconductors reported to date and large turnover numbers in sacrificial sulfur electrolyte under visible-light illumination. The newly designed electrode structure may be applicable to other photocatalytic materials and photoelectrochemical reactions.

\section{Acknowledgements}

This work is supported by JST, PREST, Japan. The authors thank the Japan Society for the Promotion of Science (JSPS) for support through a JSPS fellowship. We also thank Mr. A. Genseki at the Center for Advanced Materials Analysis in Tokyo Institute of Technology for help with the TEM observation, and also acknowledge Mr. Greg Newton for the critical reading of the manuscript. 
References

[1] M. G.Walter, E. L. Warren, J. R. McKone, S. W. Boettcher, Q. X. Mi, E. A. Santori, N. S. Lewis, Chem. Rev. 110 (2010) 6446-6473.

[2] K. Maeda, K.Domen, J. Phys. Chem. Lett. 1 (2010) 2655-2661.

[3] A. Kudo, Y.Miseki, Chem. Soc. Rev. 38 (2009) 253-28.

[4] R.Abe, J. Photoch. Photobio. C 11 (2010) 179-209.

[5] A. J. Esswein, D. G. Nocera, Chem. Rev. 107 (2007) 4022-4047.

[6] K. Nakata and, A.Fujishima, J. Photochm. Photobio. C 13 (2012) 169-189.

[7] R. Konta, T. Ishii, H. Kato, A.Kudo, J. Phys. Chem. B. 108 (2004) 8992-8995.

[8] C.Santato, M. Ulmann, J.Augustynski, Adv. Mater. 13 (2001) 511-514.

[9] A.Kay, I.; Cesar, M. J. Gratzel. J. Am. Chem. Soc. 128 (2006) 15714-15721.

[10] K. Sayama, A. Nomura, T. Arai, T. Sugita, R. Abe, M. Yanagida, T.Oi, Y. Iwasaki, Y.Abe, H. Sugihara, J. Phys. Chem. B 110 (2006) 11352-11360.

[11] S. Ida, K. Yamada, T. Matsunaga, H. Hagiwara, Y. Matsumoto, T. J. Ishihara, J. Am. Chem. Soc. 132 (2010) 17343-17345.

[12] G. Hitoki, T. Takata, J. N. Kondo, M. Hara, H. Kobayashi, K.Domen, Chem. Commun. 16 (2002) 1698-1699.

[13] H. M. Chen, C. K. Chen, Y. C. Chang, C. W. Tsai, R. S. Liu, S. F. Hu, W. S. Chang, K. H Chen, Angew. Chem. Int. Edit. 49 (2010) 5966-5969.

[14] Y. Jin-nouchi, T. Hattori, Y. Sumida, M. Fujishima, H. Tada, Chem.phys.chem. 11 (2010) 3592-3595.

[15] Y. L. Lee, C. F. Chi, S. Y. Liau, Chem. Mater. 22 (2010) 922-927.

[16] K. Zhang, L. J. Guo, Catal. Sci. Technol. 3 (2013) 1672-1690. 
[17] K. Kim, M. J. Kim, S. I. Kim, J. H. Jang, Sci Rep-Uk. (2013) 3.

[18] P. Rodenas, T. Song, P. Sudhagar, G. Marzari, H. Han, L. Badia-Bou, S. Gimenez, F. Fabregat-Santiago, I. Mora-Sero, J. Bisquert, U. Paik, Y. S. Kang, Adv. Energy. Mater. 3 (2013) 176-182.

[19] R. Trevisan, P. Rodenas, V. Gonzalez-Pedro, C. Sima, R. S. Sanchez, E. M. Barea, I. Mora-Sero, F. Fabregat-Santiago, S. Gimenez, J. Phys. Chem. Let. 4 (2013) 141-146.

[20] Z. Han, F. Qiu, R. Eisenberg, P.L. Holland, T. D. Krauss, Science 338 (2012) 1321-1324.

[21] S. Kirchmeyer, K. J. Reuter, Mater. Chem. 15 (2005) 2338-2338.

[22] S.Nagarajan, P.Sudhagar, V. Raman, K.S. Dhathathreyan and Yong Soo Kang J. Mater. Chem A 1 (2013) 1048-1054.

[23] B. Winther-Jensen, D. R. MacFarlane, Energ. Environ. Sci. 4, (2011), 2790.

[24] C. H. Chang ,Y. L. Lee, Appl. Phys. Lett. 91 (2007) 053503-1 -053503-3.

[25] M. K. Nazeeruddin, A. Kay, . Rodicio, R. Humpbry-Baker, E. Miiller, P. Liska, N. Vlachopoulos, M. Gratzel , J. Am. Chem. Soc. 115 (1993) 6382-6390.

[26] D. Kowalski, S. P. Albua, P.Schmuki, Rsc Advances 3 (2013) 2154-2157.

[27] H. Mao, X. C. Liu, D. M. Chao, L. L. Cui, Y. X. Li, W. J. Zhang, C. Wang, J. Mater. Chem. 20 (2010) 10277-10284.

[28] S. V. Selvaganesh, J. Mathiyarasu, K. L. N. Phani, V. Yegnaraman, Nanoscale Res. Lett. 2 (2007) 546-549.

[29] Chung-Wei Kung, Yu-Heng Cheng, Hsin-Wei Chen, R. Vittal and Kuo-Chuan Ho J. Mater. Chem. A 1 (2013) 10693-10702.

[30] Jae Young Kim, Ganesan Magesh, Duck Hyun Youn, Ji-Wook Jang, Jun Kubota, Kazunari Domen, Jae Sung Lee, Sci Rep. 3 (2013) 2681-1-2681-8.

[31] F. Zhang, M. Ceder, O.Inganäs, Adv. Mater. 19 (2007) 1835-1838.

[32] J. Bisquert, F. Fabregat-Santiago, I. n. Mora-Sero, G. Garcia-Belmonte, S. Gimenez, J. Phys. Chem. C 113 (2009) 17278-17290

[33] A. Zaban, M. Greenshtein, J. Bisquert, Chem.Phys.Chem. 4 (2003) 859-864. 
[34] I. Robel, V.Subramanian, M. Kuno, P. V. Kamat, J. Am. Chem. Soc. 128 (2006) 23852593.

[35] J. S. Luo, L. Ma, T. C. He, C. F. Ng, S. J. Wang, H. D. Sun, H. J. Fan, J. Phys. Chem. C 116 (2012) 11956-11963

[36] H. Kim, K. Yong, ACS Appl. Mater. Interfaces 5 (2013) 13258-13264.

[37] S. Emin, M.Fanetti, F. F. Abdi, D. Lisjak, M.Valant, R.van de Krol, B.Dam, ACS Appl. Mater. Interfaces 5 (2013) 1113-1121.

[38] Y.Wang, Journal of Physics: Conference Series. 152 (2009) 012023.

[39] A. J. Bard, M. A. Fox, Acc. Chem. Res. 28 (1995) 141-145.

[40] Z. B. Chen, T. F. Jaramillo, T. G. Deutsch, A. Kleiman-Shwarsctein, A. J. Forman, N. Gaillard, R. Garland, K. Takanabe, C. Heske, M. Sunkara, E. W. McFarland, K. Domen, E. L. Miller, J. A. Turner, H. N. Dinh, J. Mater. Res. 25 (2010) 3-16.

[41] K. Maeda, K. Teramura, T. Takata, M. Hara, N. Saito, K. Toda, Y. Inoue, H. Kobayashi , K.Domen, J. Phys. Chem. B 109 (2005) 20504-20510.

[42] X. B. Chen, S. H. Shen, L. J. Guo, S. S. Mao, Chem. Rev. 110 (2010) 6503-650.

[43] A.Thibert, F.A. Frame, E. Busby, M.A. Holmes, F.E. Osterloh, D. S. Larsen, J. Phys. Chem. Lett. 2 (2011) 2688-2694. 
Figure 1.
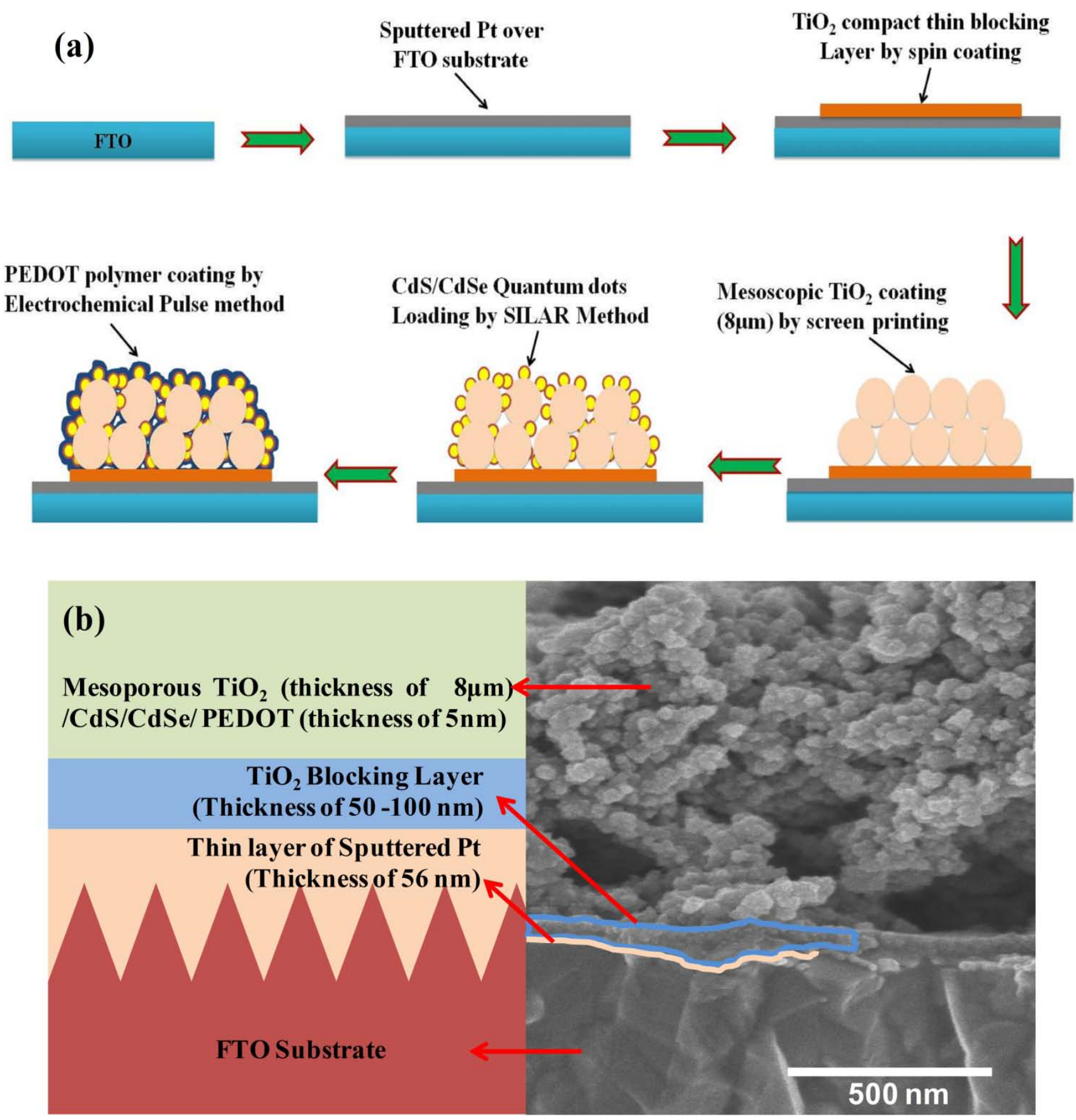

Figure 1. (a) Structural illustration of electrode construction and (b) Cross section SEM image with respect to electrode Architecture 
Figure 2.
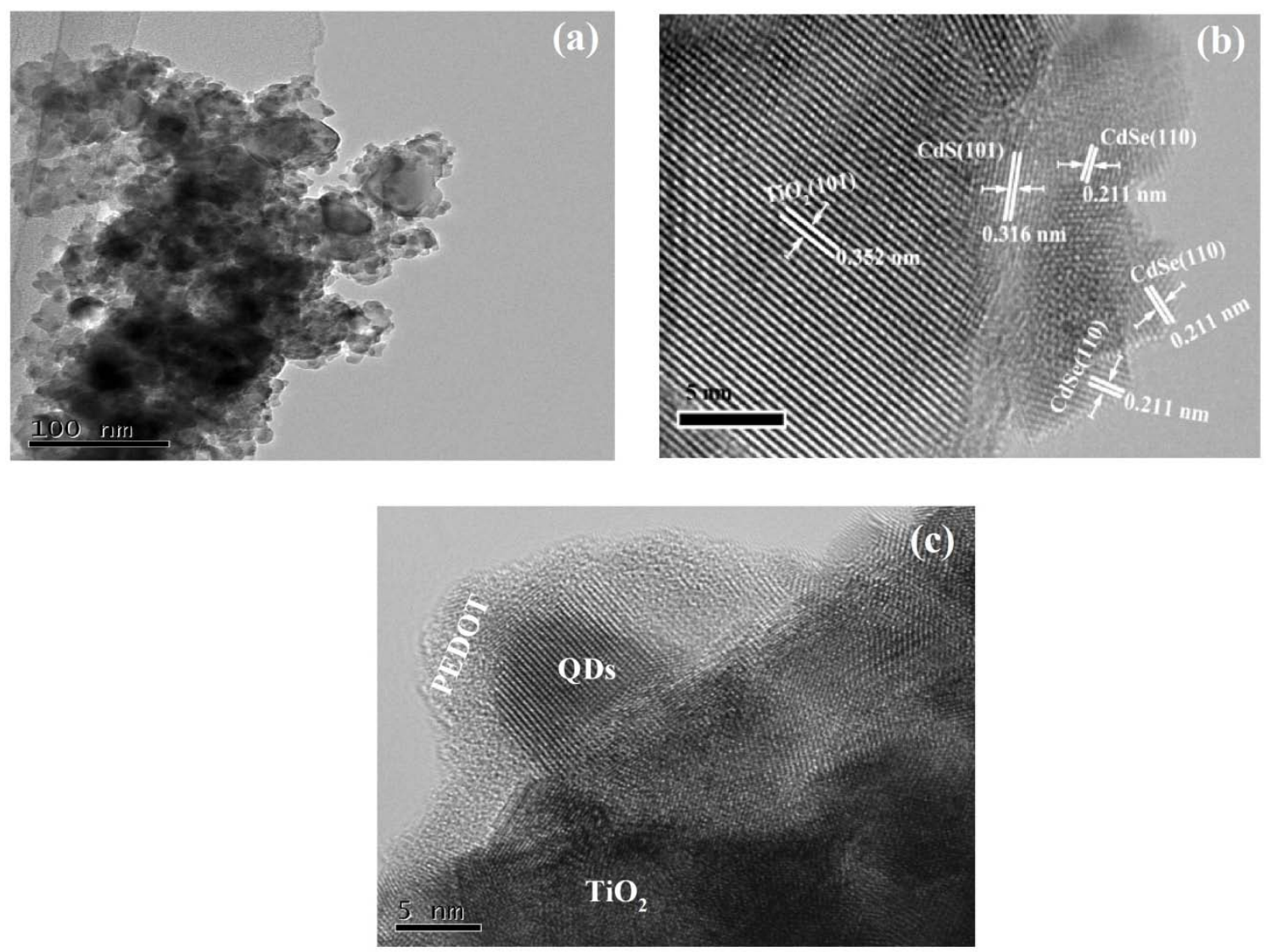

Figure 2. (a) Low magnification TEM images showing a mesoporous structure of the $\mathrm{TiO}_{2} / \mathrm{QDs}$, (b) HRTEM fringes pattern corresponds to the arrangement of CdSe and CdS quantum dots over $\mathrm{TiO}_{2}$ and (c) PEDOT polymer coated over $\mathrm{TiO}_{2} / \mathrm{QDs}$. 
Figure 3.
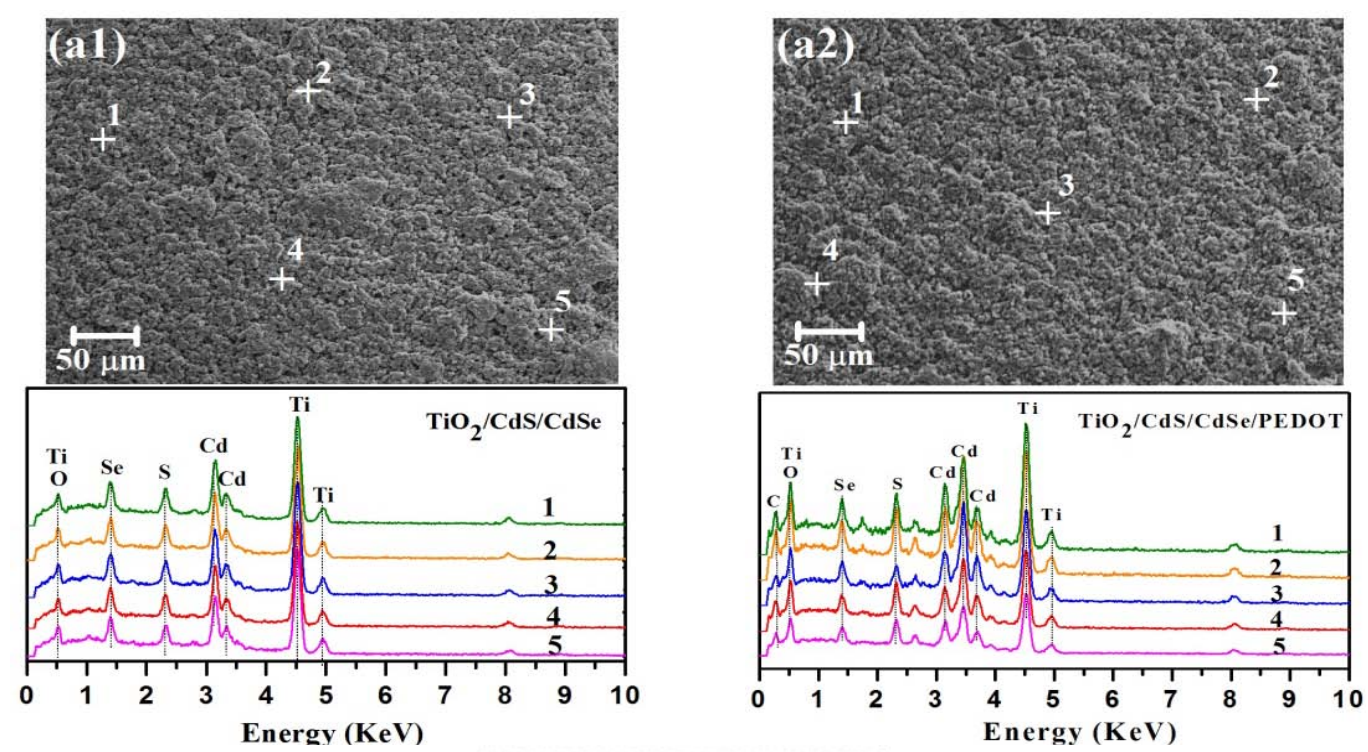

(b)
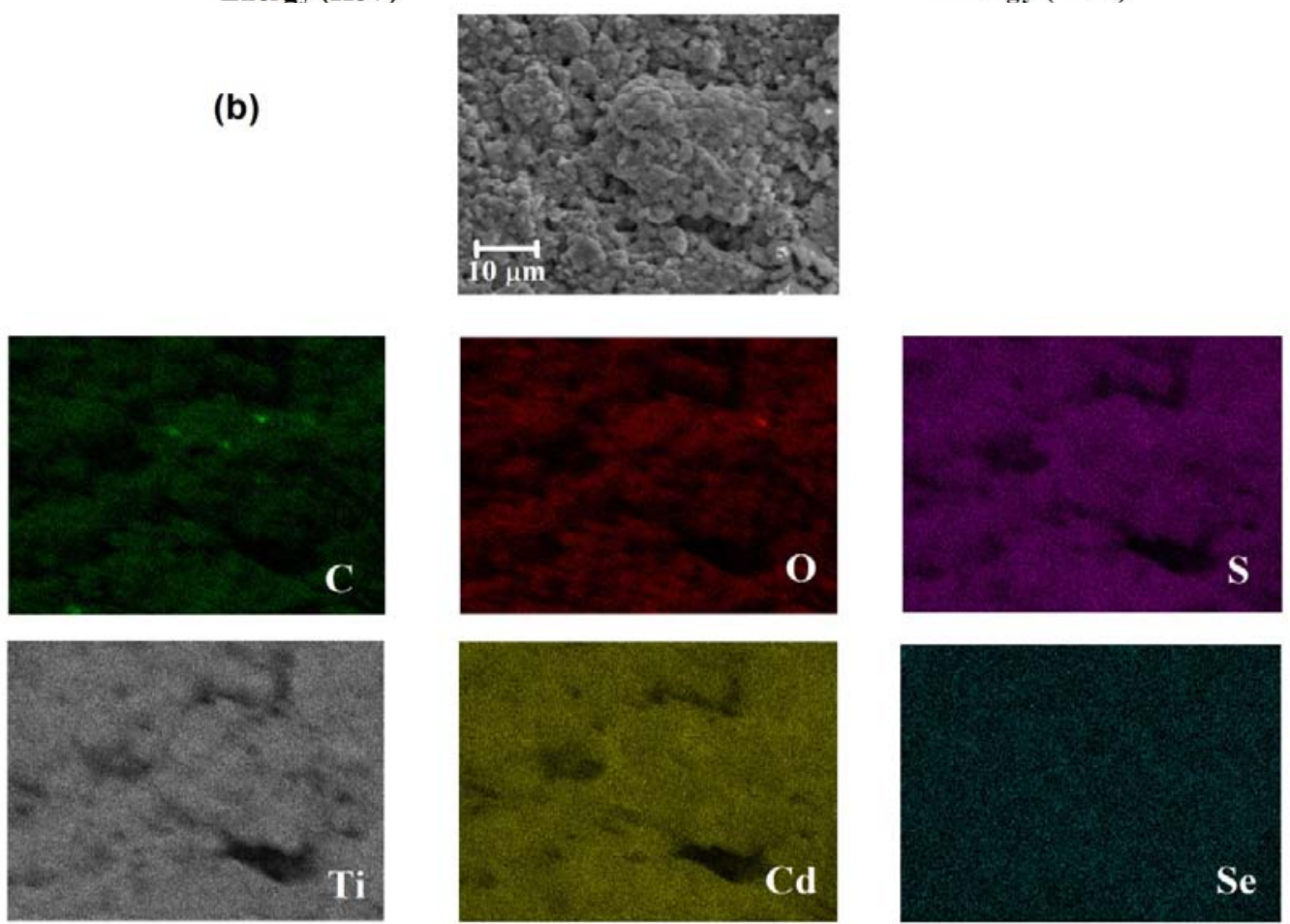

Figure 3.The EDX spot analysis and maps of (a1)TiO ${ }_{2} / \mathrm{QDs}$, (a2) $\mathrm{TiO}_{2} / \mathrm{QDs} / \mathrm{PEDOT}$ and (b) EDX elemental mapping of $\mathrm{TiO}_{2} / \mathrm{QDs} / \mathrm{PEDOT}$. 
Figure 4.

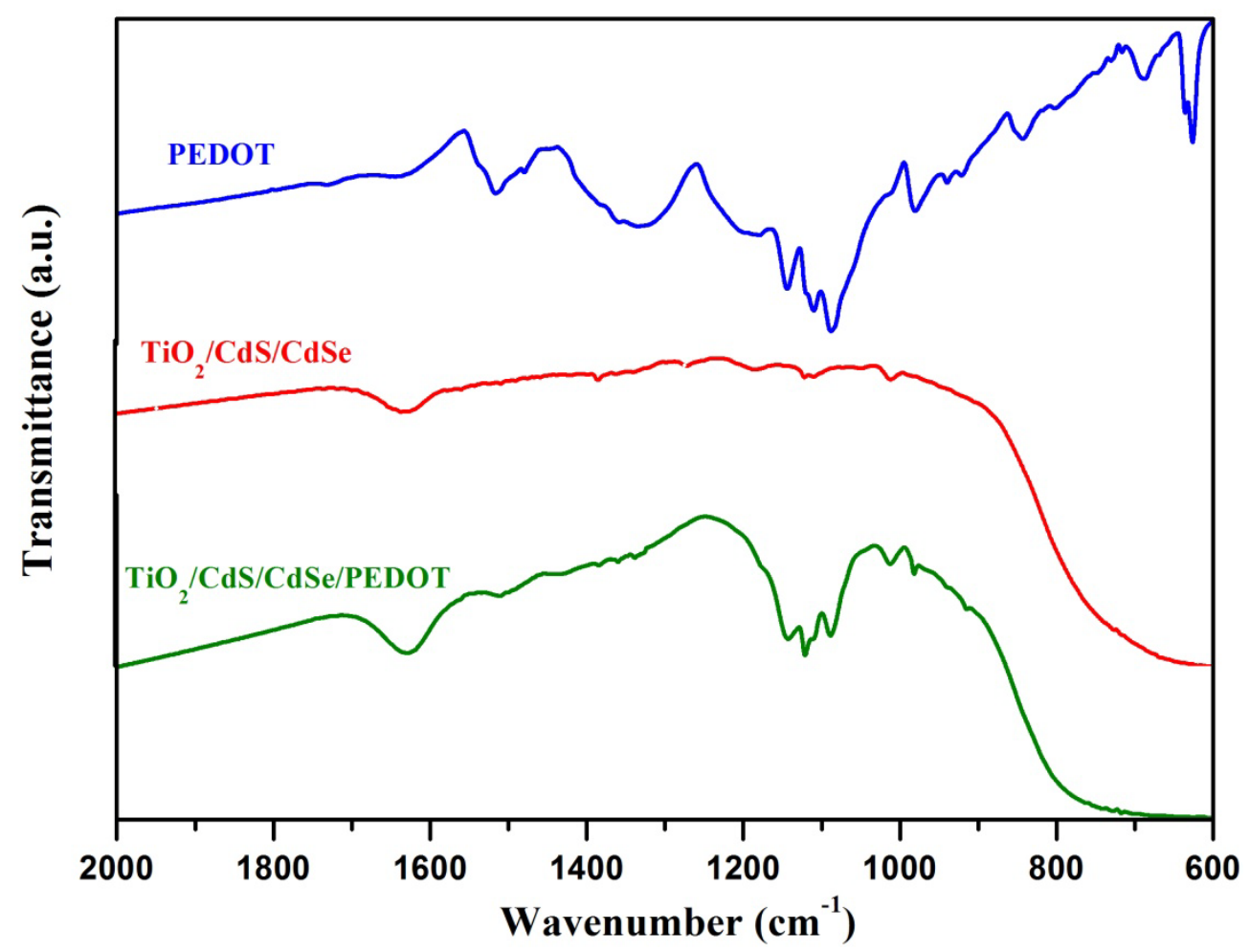

Figure 4. FTIR spectra of $\mathrm{PEDOT}, \mathrm{TiO}_{2} / \mathrm{QDs}$, and $\mathrm{TiO}_{2} / \mathrm{QDs} / \mathrm{PEDOT}$ electrodes. 
Figure 5.

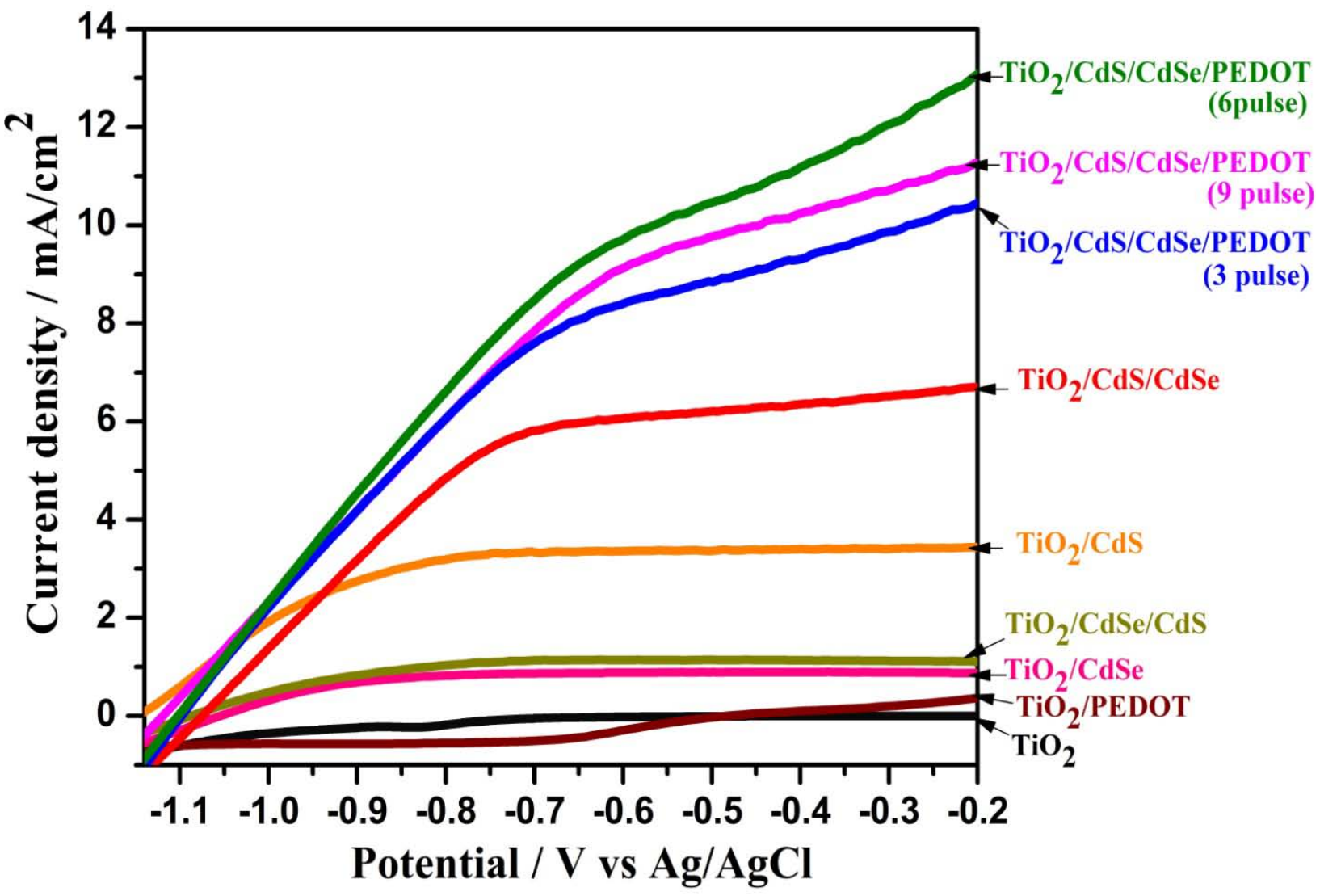

Figure 5. Current density versus potential curve measured for different photoelectrode. (Legend shows order of CdS and CdSe coated over mesoporous $\mathrm{TiO}_{2}$ ). 
Figure 6.

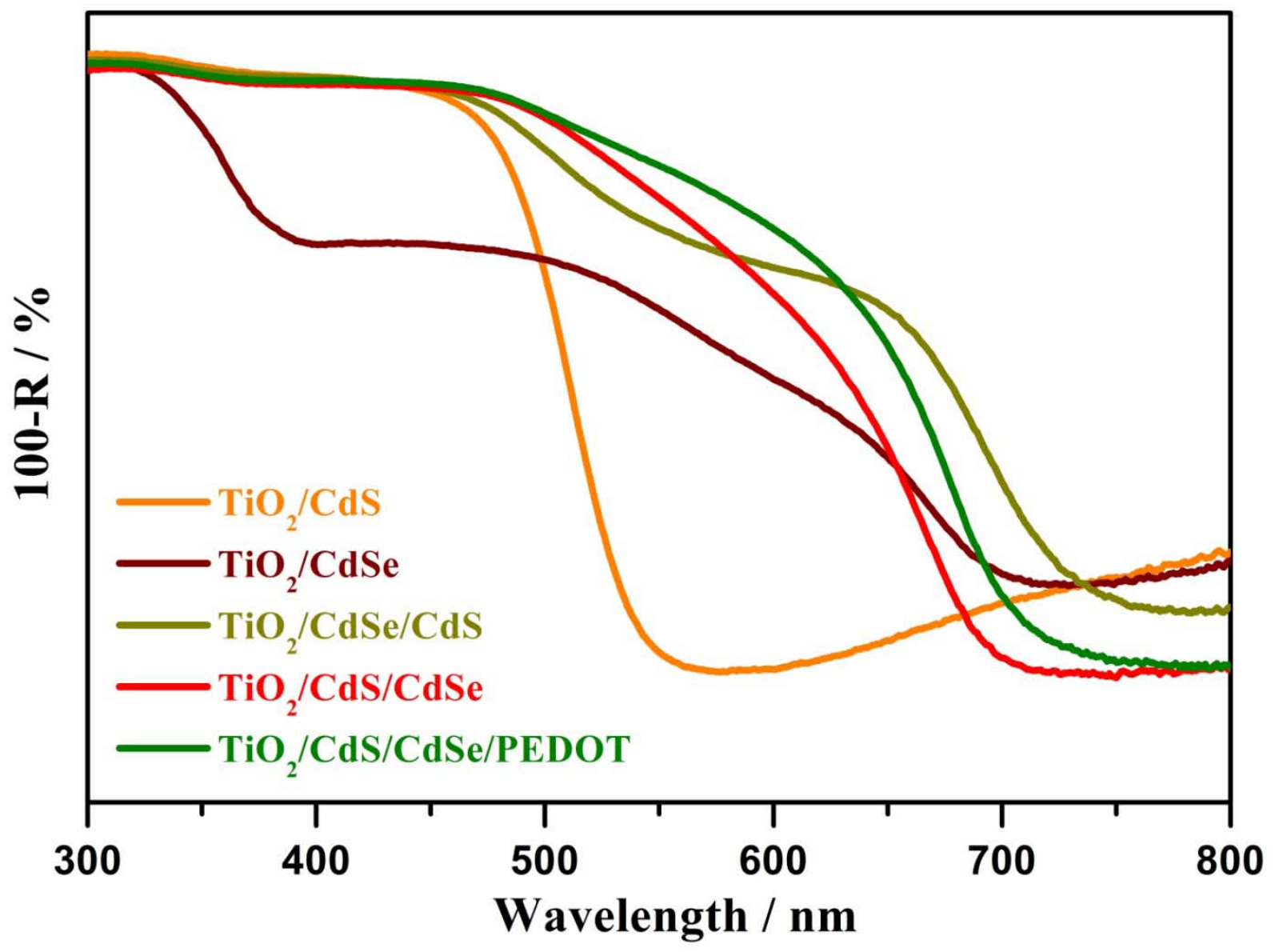

Figure 6. UV-visible absorption spectra of the different electrode measured in reflectance mode. 
Figure 7.

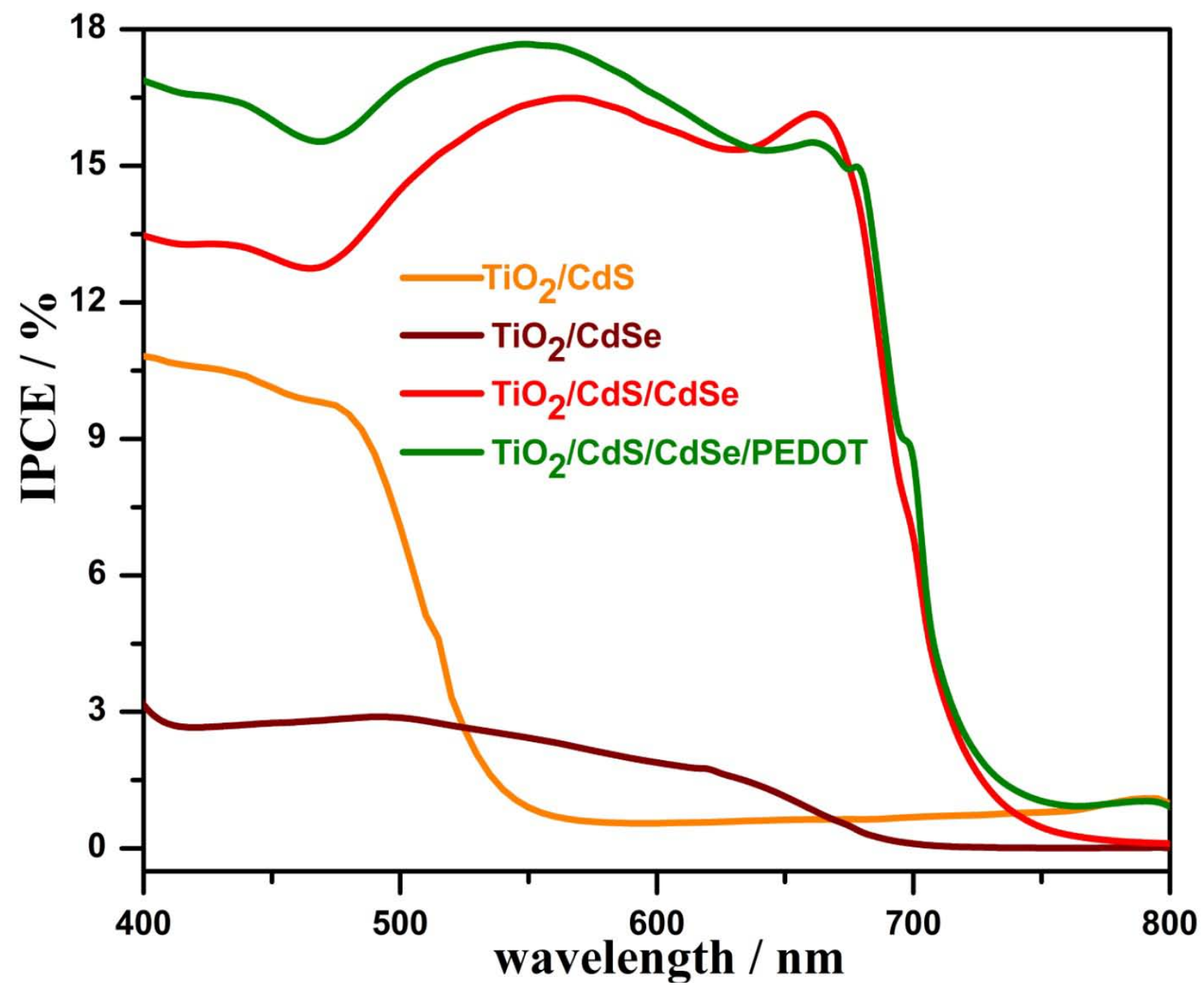

Figure 7. Incident photon to current conversion efficiencies (IPCE) for various electrodes was measured by recording the short circuit photocurrents at different excitation wavelengths. The measurement was carried out in two electrode system with $0 \mathrm{~V}$ bias potential. 
Figure 8.

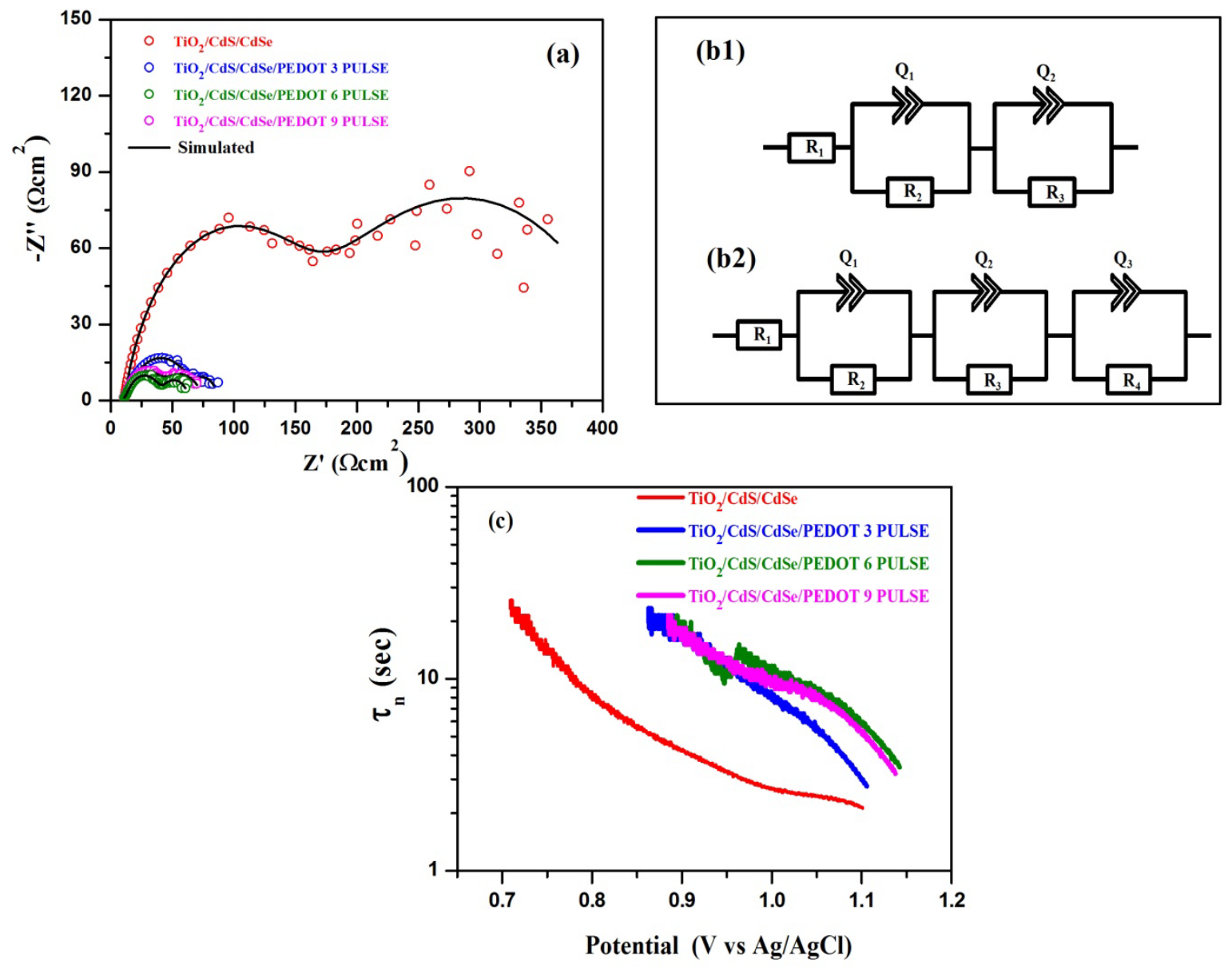

Figure 8. (a) Nyquist plots measured for different quantum dot electrodes at $\mathbf{- 0 . 5 \mathrm { V }}$ vs $\mathrm{Ag} / \mathrm{AgCl}$ in $0.24 \mathrm{M} \mathrm{Na}_{2} \mathrm{~S}$ and $0.34 \mathrm{M} \mathrm{Na}_{2} \mathrm{SO}_{3}$ electrolyte. (Bullets are experimental data and the solid line represents fitted data), (b) The corresponding fitted equivalent circuit model and (c) Electron lifetime as a function of open circuit voltage $\left(V_{o c}\right)$ derived from the $V_{o c}$ decay for different electrodes. 
Figure 9.

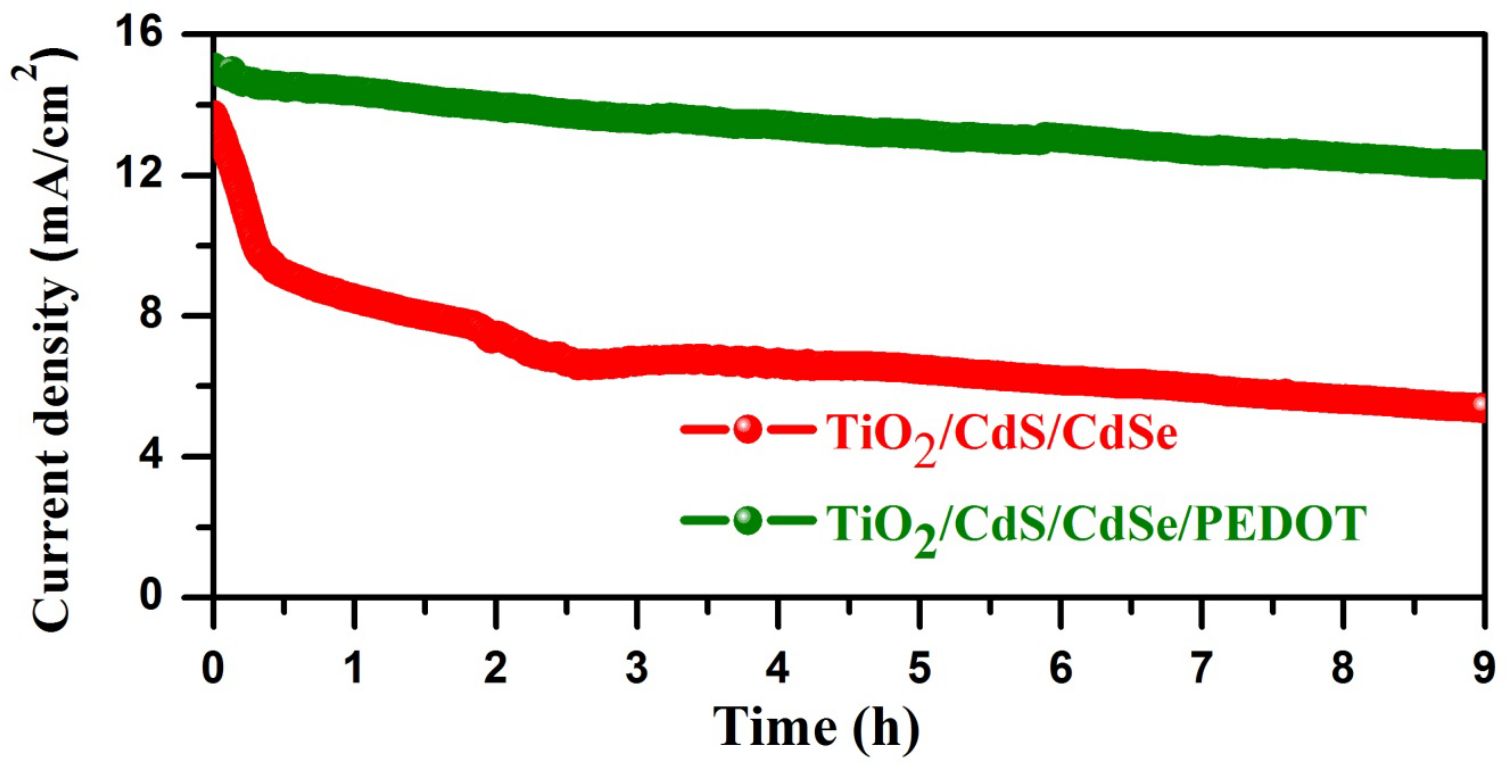

Figure 9. Photo stability of $\mathrm{TiO}_{2} / \mathrm{QDs}$ and $\mathrm{TiO}_{2} / \mathrm{QDs} / \mathrm{PEDOT}$ electrode measured by photocurrent over time in $0.34 \mathrm{M} \mathrm{Na}_{2} \mathrm{SO}_{3}, 0.24 \mathrm{M} \mathrm{Na} \mathrm{S}_{2}$ electrolyte solution with applied bias potential of $0 \mathrm{~V}$ vs Ag/AgCl under visible light illumination from a $150 \mathrm{~W}$ Xe lamp equipped with an UV cut-off filter below $430 \mathrm{~nm}$. 
Figure 10.

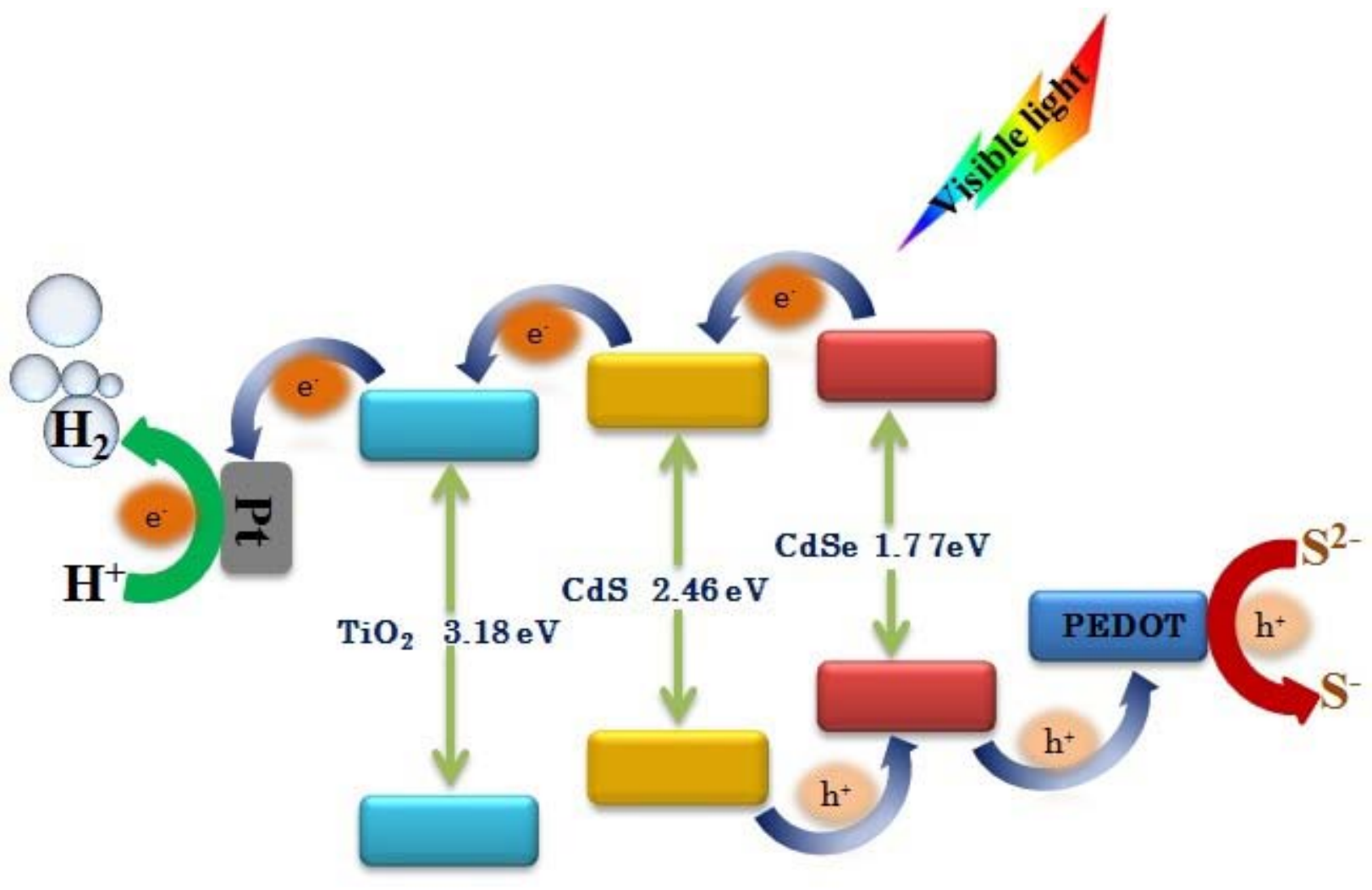

Figure 10. Schematic illustration of electronic band structure and the respective photogenerated charge transfer mechanism for hydrogen generation in $\mathrm{Pt} / \mathrm{TiO}_{2} / \mathrm{QDs} / \mathrm{PEDOT}$ electrode. 
Figure 11
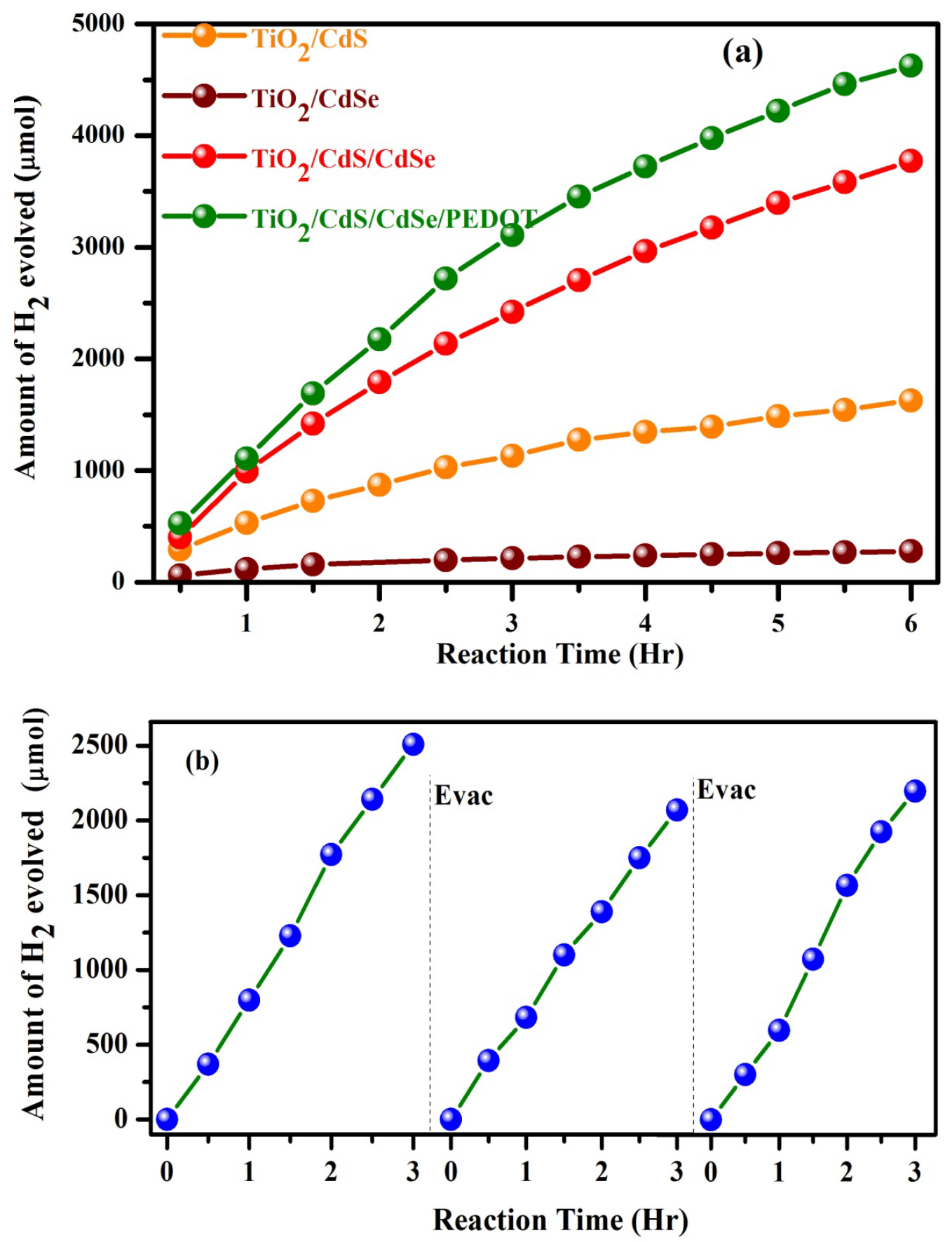

Figure 11. (a) Photocatalytic hydrogen evolution from $\mathrm{TiO}_{2} / \mathrm{CdS}, \mathrm{TiO}_{2} / \mathrm{CdSe}, \mathrm{TiO}_{2} / \mathrm{QDS}$ and PEDOT coated $\mathrm{TiO}_{2} / \mathrm{QDS}$ electrodes.(b) Time course of photocatalytic hydrogen evolution for PEDOT coated $\mathrm{TiO}_{2} / \mathrm{QDS}$ electrode (surface area of $4 \mathrm{~cm}^{2}$ ) in $0.34 \mathrm{M} \mathrm{Na} \mathrm{SO}_{3}$, 
$0.24 \mathrm{M} \mathrm{Na} \mathrm{Na}_{2}$ electrolyte solution under visible light illumination from a $150 \mathrm{~W}$ Xe lamp equipped with an UV cut-off filter below $430 \mathrm{~nm}$. 